\title{
How the methodology of 3D structure preparation influences the quality of QSPR models?
}

\author{
Stanislav Geidl", Roman Beránek, Radka Svobodová Vařeková, Tomáš Bouchal, Miroslav Brumovský, Michal Kudera, \\ Ondřej Skřehota, Jaroslav Koča
}

From 7th German Conference on Chemoinformatics: 25 CIC-Workshop

Goslar, Germany. 6-8 November 2011

QSPR modelling is a very useful and popular methodology for estimating the physical and chemical properties of molecules. The inputs for QSPR models are 3D structures of molecules. Currently, the 3D structures for millions of molecules are publicly available. A large number of these 3D structures were generated by software tools for the conversion of 2D structures into 3D. Moreover, the generated structures can be geometrically optimized by different approaches, such as molecular mechanics, quantum mechanics, etc.. The question arises as to how the methodology of 3D structure preparation influences the quality of QSPR models that use these structures. Is there some software tool for 3D structure construction more suitable for QSPR modelling purposes than others? Conversely, which software tools are inappropriate? How strong is the influence of the geometry optimization procedure? We focused on these questions in the present study.

In our work, we analyzed the influence of 3D structure preparation methodology on the quality of QSPR models for the prediction of the acid dissociation constant $\left(\mathrm{pK}_{\mathrm{a}}\right)$ from atomic charges [1]. We employed three different software tools for 3D structure generation (Corina [2], Balloon [3], etc.), together with two approaches for geometry optimization. This way, we prepared nine sets of 3D structures, and used them to develop QSPR models based on several different charge calculation schemes. Afterwards, we compared the accuracy of these QSPR models and discussed the influence of the methodology for 3D structure preparation.

National Centre for Biomolecular Research and CEITEC - Central European Institute of Technology, Masaryk University, Brno, Czech Republic, 625 00, CZ
Published: 1 May 2012

\section{References}

1. Svobodová Vařeková R, Geidl S, lonescu CM, Skřehota O, Kudera M, Sehnal D, Bouchal T, Abagyan R, Huber JH, Koča J: Predicting $\mathrm{pK}_{\mathrm{a}}$ values of substituted phenols from atomic charges. J Chem Inf Model 2011, 51:1795-1806

2. Sadowski J, Gasteiger J: From atoms and bonds to three-dimensional atomic coordinates: Automatic model builders. Chem Rev 1993, 93:2567-2581.

3. Vainio MJ, Johnson MS: Generating conformer ensembles using a multiobjective genetic algorithm. J Chem Inf Model 2007, 47:2462-2474.

\section{doi:10.1186/1758-2946-4-S1-P61}

Cite this article as: Geidl et al:: How the methodology of 3D structure preparation influences the quality of QSPR models? Journal of Cheminformatics 2012 4(Suppl 1):P61.

\section{Publish with ChemistryCentral and every scientist can read your work free of charge \\ "Open access provides opportunities to our colleagues in other parts of the globe, by allowing anyone to view the content free of charge." \\ W. Jeffery Hurst, The Hershey Company. \\ - available free of charge to the entire scientific community \\ - peer reviewed and published immediately upon acceptance \\ - cited in PubMed and archived on PubMed Central \\ - yours - you keep the copyright \\ Submit your manuscript here: \\ http://www.chemistrycentral.com/manuscript/

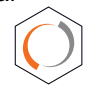 Chemistry Central}

